\title{
Dexlansoprazole - a new-generation proton pump inhibitor
}

\author{
Barbara Skrzydło-Radomańska, Piotr Radwan \\ Chair and Department of Gastroenterology, Medical University of Lublin, Lublin, Poland
}

Prz Gastroenterol 2015; 10 (4): 191-196

DOI: $10.5114 / p g .2015 .56109$

Key words: proton pump inhibitor, dexlansoprazole, R-enantiomer, treatment of gastroesophageal reflux disease.

Address for correspondence: Prof. Barbara Skrzydło-Radomańska MD, PhD, Chair and Department of Gastroenterology, Medical University of Lublin, 8 Jaczewskiego St, 20-950 Lublin, Poland, e-mail: barbara.radomanska@gmail.com

\begin{abstract}
Dexlansoprazole modified release (MR) is an R-enantiomer of lansoprazole and a new-generation proton pump inhibitor exhibiting high efficacy in the treatment of symptoms and lesions associated with erosive oesophagitis caused by gastroesophageal reflux disease (GERD). The dual release of the active ingredient - in the duodenum and the small intestine - makes it possible to achieve two peak concentrations at various times, within two and five hours of administration. Dexlansoprazole MR ensures the longest maintenance of drug concentration in the plasma of all known proton pump inhibitors, and the longest proton pump inhibitory effect. The basic indications for the drug include all forms of gastroesophageal reflux disease, especially with nighttime heartburn and sleep disorders resulting from GERD. Dexlansoprazole can be taken regardless of meal times. It has a good safety profile and carries a low risk of adverse interactions with other drugs.
\end{abstract}

\section{Introduction}

Proton pump inhibitors (PPI), used in the treatment of hydrochloric acid-related diseases, are currently among the most commonly prescribed drugs worldwide. Their popularity stems from the high efficacy in inhibiting gastric acid secretion, selectivity of action and few adverse reactions. The discovery of PPIs radically changed the therapeutic approach to diseases caused by excessive secretion of acidic gastric juices. At present, PPIs are the most widely used and the strongest-acting antisecretive drugs. High efficacy in inhibiting the production of gastric hydrochloric acid stems from the effect of PPIs on basic and stimulated secretion [1].

The mechanism of action of PPIs is based on inhibiting the activity of the enzyme hydrogen/potassium adenosine triphosphatase (H/K ATPase) called the proton pump and found in parietal cells of the gastric mucosa. H/K ATPase is involved in the secretion of hydrochloric acid, hydrolyzing ATP and exchanging $\mathrm{H}^{+}$ions from the cytoplasm for $\mathrm{K}^{+}$ions in the secretory canaliculus, which results in $\mathrm{HCl}$ secretion into the gastric lumen [1-3]. Proton pump inhibitors are benzimidazole compounds and occur in the form of pro-drugs. All proton pump inhibitors demonstrate a high degree of activation in the acidic environment. After passing through the liver and reaching the gastric parietal cells activated by a meal, PPIs undergo protonation in the acidic $\mathrm{pH}$ environment, followed by conversion to sulphenamide which represents the active form of the drug. Sulphenamide inhibits the activity of the proton pump and hence the transport of hydrogen ions into the gastric lumen via covalent binding to the $\mathrm{SH}$ groups of the cysteine residues of $\mathrm{H} / \mathrm{K}$ ATPase.

\section{Indications for proton pump inhibitors therapy}

Proton pump inhibitors are widely used in the therapeutic management of hydrochloric acid-related diseases, including the treatment of symptoms and healing of erosive oesophagitis, treatment of complications and prevention of gastroesophageal reflux disease (GERD) recurrence, therapy of peptic ulcer disease, eradication of Helicobacter pylori bacteria, functional dyspepsia, prevention and healing of gastroduodenal mucosal injury induced by nonsteroidal anti-inflammatory drugs (NSAIDs) and in Zollinger-Ellison syndrome and systemic mastocytosis. In addition to the indications listed above, PPIs are also used in other clinical conditions, e.g. in the pharmacotherapy of non-variceal upper gastrointestinal bleeding, prevention of aspiration pneumonia, and 
in intensive care units (ICU) to prevent stress-related mucosal damage (SRMD) in severely ill patients [4-6].

The first proton pump inhibitor and the prototype drug for other PPIs is omeprazole, which has been on the pharmaceutical market since 1989. Since that time, other proton pump inhibitors have also been successively incorporated into clinical practice, including lansoprazole, rabeprazole and pantoprazole. The PPIs enumerated here are racemic mixtures of enantiomers, i.e. optical right- and left-handed isomers [3]. The year 2001 saw the market launch of esomeprazole, the first inhibitor produced in the form of an optical isomer and being a left-handed (S)-isomer of omeprazole. The newest drug in this class, which has been available for hyposecretory treatment since 2009 in the USA and since 2015 in Poland (the second country in Europe after Switzerland) is dexlansoprazole, a right-handed (R)-isomer of lansoprazole marketed under the brand name Dexilant.

\section{Characteristics and pharmacological properties of dexlansoprazole}

Due to its unique formula, dexlansoprazole can be referred to as a new-generation proton pump inhibitor. A modification of the chemical structure and pharmaceutical form of the drug has improved its bioavailability and metabolism, and the efficiency of inhibiting the proton pump function in the parietal cells of the gastric mucosa. The pharmaceutical form of dexlansoprazole is based on the unique technology of modified dual release. The active ingredient is released in two phases at different $\mathrm{pH}$ values and with a time interval. Consequently, the drug achieves two peak concentrations in the blood, and the total serum concentration of dexlansoprazole is three times higher than that of the left-handed enantiomer. Also, dexlansoprazole has a lower elimination rate than S-lansoprazole and persists longer in the serum. It inhibits acid secretion for a longer period, and its AUC (area under the curve) values are 3-5 times higher than those determined for the racemic mixture or the left-handed isomer [7-10]. The active ingredient in the form of two types of granules is released from a Dexilant capsule twice, at different $\mathrm{pH}$ values. One part, representing $25 \%$ of the drug dose, is released at the $\mathrm{pH}$ level of 5.5 in the proximal duodenum. The remaining part $(75 \%)$ are released in the distal small intestine, where the $\mathrm{pH}$ is 6.75 . This dual release mechanism makes it possible to achieve two peak serum concentrations of the drug: one within 1-2 $\mathrm{h}$ and the other within 4-5 h after administration. Consequently, dexlansoprazole modified release ensures the longest period of drug retention in the circulation and the most powerful inhibitory effect on the proton pump of all available proton pump inhibitors [8, 9, 11].
As is commonly known, all PPIs used to date required compliance with a defined time interval. The drug had to be taken 30-60 min before a meal, so that after being absorbed from the gastrointestinal tract and passing through the hepatic enzymatic system it can reach active (meal-activated) proton pumps in order to inhibit their function in the most effective manner possible. In this respect, dexlansoprazole is an exceptional drug because it relieves patients of the need to maintain a strict regime with regard to meal times and drug intake at specific times in relation to meals, and drug efficacy is independent of these factors [12-14]. It is a widely recognized fact that patients fail to adhere to therapy and insufficiently comply with recommendations which make drug-taking times conditional on meal times and require an appropriate interval between them. Only about 40\% take PPIs in line with recommendations, which results in weaker inhibition of acid secretion and represents one of the causes of therapeutic failure $[15,16]$. It is also associated with the observed difference in PPIs efficacy between clinical trials and daily practice. The participants of clinical trials are a selected group of patients whose therapy method can not be transposed to everyday practice. The significant factor influencing the efficacy of classic proton pump inhibitors is closely monitoring the time the administration and usage of drugs in clinical trials.

As a result, the efficacy of treatment in clinical trials is much higher than in daily practice. Therefore, an essential advantage of improving cooperation (compliance) of the patients and the effectiveness of the therapy is the fact that the administration of Dexialnt after or before breakfast, lunch, dinner or evening snack has no clinically significant effect on intragastric $\mathrm{pH}$ control during the day.

The mean percentages of time during which the $\mathrm{pH}$ level in the stomach was $>4$ over a 24-hour period after drug intake were $71 \%, 74 \%, 70 \%$ and $64 \%$, respectively, for the regimens of taking the drug before the meals listed above. As a result, dexlansoprazole maintains appropriate plasma concentrations and a therapeutic effect for a longer period than PPIs with a single release mechanism, and the efficacy of Dexilant is independent of meal times $[13,14]$.

The effectiveness of the suppressing effect produced by a proton pump inhibitor upon hydrochloric acid secretion is expressed by the time during a 24-hour period when the intragastric $\mathrm{pH}$ level can be maintained above 4 because then the activity of pepsin - previously activated from pepsinogen in the acidic environment - radically drops and remains at a minimum level. The elimination of the destructive effect of pepsin in the increasing $\mathrm{pH}$ environment supports the healing of morphological features of mucosal damage in the upper 
gastrointestinal tract (erosions and ulcers) and removes subjective symptoms $[1,2]$.

\section{Dexlansoprazole in the treatment of gastroesophageal reflux disease}

At present, the basic indication for using dexlansoprazole is gastroesophageal reflux disease in all its forms, i.e. non-erosive reflux disease (NERD) with symptoms present during the day or at night causing sleep disorders, and erosive oesophagitis of all severity grades. A particularly intensive treatment suppressing the secretion of gastric acid is necessary in patients with severe erosive oesophagitis (grades $C$ and D according to the Los Angeles classification, in which coalescing epithelial erosions involve a considerable part or the entire oesophageal circumference). Healing such severe lesions requires a powerful suppressive effect on the secretion of acidic gastric juice using fixed therapeutic doses in maintenance treatment, because the incidence of recurrence of erosive oesophagitis in this form of GERD exceeds $90 \%$ during 6 months $[2,12,16,17]$.

It is known that some GERD patients (17-35\%) treated with omeprazole or other proton pump inhibitors continue experiencing symptoms of the disease [17-20]. Studies show that up to $35.4 \%$ of patients and $34.8 \%$ of physicians are not fully satisfied with the outcome of treatment based on traditional PPIs [21]. The resistance to hyposecretory treatment can arise from a variety of factors. Some of them are physician-related (incorrect diagnosis, inappropriate drug dose, insufficiently long treatment), others - patient-related (lack of compliance, genotypic differences determining drug metabolism), and yet others - drug-related (duration of maintaining gastric $\mathrm{pH}$ above 4). One of the causes underlying the inefficacy of PPIs in the treatment of GERD can also be non-acidic reflux or nocturnal acid breakthrough in the stomach accompanied by sleep disorders [22, 23]. Another problem relates to inappropriate diagnosis, with GERD diagnosed instead of functional heartburn, eosinophilic oesophagitis, early achalasia of the cardia, autoimmune diseases or coexisting mental disorders $[18,19,21,23,24]$. Therefore, aside from the verification of diagnosis, other options should also be considered in an attempt to improve therapeutic outcomes, such as prolongation of therapy, dose increase or substitution of the inhibitor for another. The newest of them is dexlansoprazole. A comparative study performed in healthy volunteers to determine the effect of a single dose of dexlansoprazole $60 \mathrm{mg}$ and esomeprazole $40 \mathrm{mg}$ on the mean gastric $\mathrm{pH}$ value over $24 \mathrm{~h}$ and the percentage of time with $\mathrm{pH}>4$ has revealed the following statistically significant differences: 4.3 vs. $3.7(p=0.003)$ and $58 \%$ vs. $48 \%(p<0.001)$, respectively [25].
As opposed to studies comparing the effect of different PPIs used to date on the production of hydrochloric acid in the stomach in physiological conditions in healthy volunteers, there have been no significant differences in terms of their clinical efficacy in the treatment of GERD patients, however very favourable results for dexlansoprazole, obtained in well-designed clinical trials, have been published in recent years.

Clinical trials have assessed the efficacy of dexlansoprazole in GERD in aspects related to the subsidence of daytime and nocturnal symptoms including sleep disorders, healing of mucosal injury in erosive oesophagitis and maintenance of the healing effect on erosive lesions. In one of the trials, involving patients with the non-erosive form of the disease, heartburn was eliminated within 4 weeks in $50 \%$ of the patients receiving dexlansoprazole MR at a dose of $60 \mathrm{mg}$, in $55 \%$ of the patients treated with the $30 \mathrm{mg}$ dose, and in $19 \%$ of the placebo patients [9]. An indirect comparison of randomized studies assessing the activity of two proton pump inhibitors in the isomeric form - dexlansoprazole 60 and esomeprazole 40 - in the elimination of symptoms and healing of erosions in GERD patients has shown the two PPIs to have a similar efficacy in healing, and dexlansoprazole to be much more effective in alleviating symptoms in NERD patients [26]. As expected, due to its unique pharmacodynamic properties, dexlansoprazole brings a considerable relief to patients suffering from night-time heartburn and sleep disorders caused by GERD. In a 4-week study of 947 patients diagnosed with the non-erosive form of GERD divided into groups receiving the study drug at doses of 30 or $60 \mathrm{mg}$ or placebo, based on patients' assessment dexlansoprazole $30 \mathrm{mg}$ has provided a statistically significant higher percentage of days without heartburn for $24 \mathrm{~h}$ and heartburn-free nights (54.9\% and $80.8 \%$, respectively) than the placebo ( $18.5 \%$ and $51.7 \%$, respectively). Importantly, the other study dose $(60 \mathrm{mg})$ failed to provide any additional benefit over the $30 \mathrm{mg}$ dose [27]. Another randomized multicentre trial has involved 305 patients with night-time heartburn and GERD-related sleep disorders. The patients took $30 \mathrm{mg}$ of dexlansoprazole or placebo once daily for a total of 4 weeks. The study drug ensured a statistically significant higher percentage of heartburn-free nights (73.1\%) than placebo (35.7\%), and the proportions of patients without sleep disorders after the therapy were, respectively, $69.7 \%$ vs. $47.9 \%$ $(p<0.001)$ [28].

The healing of reflux erosive oesophagitis has been investigated in two randomized active controlled studies spanning 8 weeks, conducted in a total of 4,092 patients with endoscopically confirmed erosive oesophagitis based on the Los Angeles classification. The analysis 
showed that after 8 weeks of treatment with dexlansoprazole $60 \mathrm{mg}$ the lesions had been healed in 92.3-93.1\% of the patients compared to $86.1-91.5 \%$ of the patients receiving $30 \mathrm{mg}$ of lansoprazole across the entire treated group. In the subgroup of subjects with moderate or severe erosive oesophagitis (grades $C$ and $D$ ), the percentages were: $88.9 \%$ of the patients cured with the study drug and $74.5 \%$ cured with lansoprazole. It must be stressed that the same clinical sample was also used for studying dexlansoprazole at a dose of $90 \mathrm{mg}$, however without confirming any additional benefits [29].

Reflux erosive oesophagitis is characterized by a high propensity for recurrence. The disease recurs in 89-90\% of cases during 6-12 months. In patients with grades $C$ and $D$ reducing the dose of a proton pump inhibitor is sufficient for causing a recurrence in up to $41 \%$ of cases over a 6 -month period [30]. Consequently, a multi-centre randomized placebo-controlled clinical trial was conducted in a group of 445 patients who successfully completed a therapy of erosive oesophagitis, as verified by endoscopic evidence. The maintenance of the therapeutic effect and the alleviation of symptoms were assessed for dexlansoprazole at doses of 30 and $60 \mathrm{mg}$, compared to placebo, for a period of 6 months. The maintenance of healing rates in reflux oesophagitis achieved for the medicinal product at both doses were $74.9 \%$ and $82.5 \%$ respectively, and were thus significantly higher than for placebo (27.2\%) both in the whole study group and in the subgroup of patients with more severe oesophagitis (grades C and D). The percentage for the maintenance of heartburn relief during the study was also higher in a statistically significant manner. The median of the percentage of heartburn-free days over $24 \mathrm{~h}$ was $96.1 \%, 90.9 \%$ and $28.6 \%$ for the 30 and $60 \mathrm{mg}$ doses of the drug and the placebo, respectively, and the median of the percentage of heartburn-free nights was 98.9\%, 96.2\% and 71.7\% [31]. In maintenance treatment, during six months of study, there was no statistically significant difference in activity between the 30 and $60 \mathrm{mg}$ doses. The results show that dexlansoprazole $60 \mathrm{mg}$ provides high (92\%) healing rates of erosive oesophagitis over a period of 8 weeks, and dexlansoprazole $30 \mathrm{mg}$ effectively maintains the healing of lesions associated with reflux erosive oesophagitis [29, 31].

An interesting multi-centre single-blind study has been conducted in a group of 178 patients with symptomatic GERD, who were previously successfully treated with a proton pump inhibitor taken twice a day. The study patients received dexlansoprazole $30 \mathrm{mg}$ in the morning and placebo in the evening for 6 weeks in blind sample conditions. A good control of symptoms was defined as a mean weekly number of heartburn episodes smaller than or equal to 1 . Following the change of treatment from a PPI taken twice a day to dexlansoprazole $30 \mathrm{mg}$ once daily, heartburn continued to be well-controlled in $88 \%$ of the patients [32].

\section{Interactions of dexlansoprazole with other drugs}

For the practising physician, a crucial aspect to consider is the potential risk of interactions between concurrently used medicinal products. Dexlansoprazole is intensively metabolized in the liver by oxidation and reduction followed by conjugation with sulphates, glucuronate and glutathione to inactive metabolites. Metabolites of oxidation arise through the activity of the cytochrome P450 (CYP) enzymatic system via hydroxylation, mainly by CYP2C19, and oxidation to sulphone by CYP3A4. In patients with moderate and intensive CYP2C19 metabolism the main plasma metabolite is 5-hydroxy dexlansoprazole and its glucuronate, and in patients with weak CYP2C19 metabolism the main plasma metabolite is the sulphonic metabolite $[8,10$, 11, 33]. Therapy with drugs having the ability to inhibit the CYP2C19 isoenzyme (e.g. fluvoxamine) can increase the systemic exposure to dexlansoprazole. In contrast, CYP2C19- and CYP3A4-inducing drugs (rifampicin, St. John's wort extract) can reduce the plasma concentration of dexlansoprazole [8, 10, 33].

Similarly to other proton pump inhibiting drugs, dexlansoprazole can interfere with the absorption of drugs whose bioavailability depends on the $\mathrm{pH}$ value of the gastric juice. Dexlansoprazole should not be used in conjunction with atazanavir and nelfinavir due to a reduced systemic exposure to the drugs. The absorption of ketoconazole, itraconazole and erlotinib also depends on low $\mathrm{pH}$ values, so their use in conjunction with dexlansoprazole should be avoided. In contrast, no effect on the pharmacokinetics has been found for concurrently used phenytoin, theophylline or diazepam. However, the administration of digoxin and tacrolimus in conjunction with dexlansoprazole can cause an increase in their plasma concentration. Consequently, the concentrations of these drugs must be monitored at the beginning and at the end of therapy, with dose adjustments, if required. In the case of tacrolimus, the above reservation applies in particular to transplant recipients with a moderate or slow metabolism involving CYP2C19 (tacrolimus is a substrate for the CYP3A4 isoenzyme).

A very important property of dexlansoprazole, however, is the fact that it has no clinically significant pharmacokinetic interactions with thienopirydyne derivatives, particularly clopidogrel. Consequently, there is no need for dose adjustment if the above drugs are used concurrently in approved doses [8, 33, 34]. 


\section{Safety}

Clinical experiences gathered in a group exceeding 4,500 patients and assessed in seven clinical trials indicate that dexlansoprazole is characterized by a good safety profile and rarely produces adverse reactions which generally do not require drug discontinuation. The safety of use of dexlansoprazole at doses of 30 , 60 and $90 \mathrm{mg}$ following oral administration has been assessed in clinical trials covering a period of 1 year. The observed adverse drug reactions were mild or moderate, and their frequency was comparable to or lower than those recorded for the placebo or lansoprazole. The most commonly reported adverse effects included diarrhoea (cause of treatment discontinuation in $0.7 \%$ of cases), stomach ache, headache, nausea, abdominal discomfort, flatulence and constipation $[8,11,35]$.

In Poland, dexlansoprazole is not approved for use in children. However, there are publications reporting trials investigating the pharmacokinetics and safety of dexlansoprazole in the treatment of symptomatic GERD in adolescents aged between 12 and 17 years and in paediatric patients aged between 1 and 11 years $[36,37]$. The pharmacokinetics and efficacy of dexlansoprazole have been found to be similar to the adult population, and the drug has been well-tolerated by children and adolescents.

According to medical indications, some forms and complications of GERD require PPIs to be taken on a chronic basis. Such indications include, for example, erosive oesophagitis grades $C$ and D (based on the Los Angeles classification), Barrett's metaplasia or oesophageal stricture. Therefore, it is worthwhile to mention trial results demonstrating the efficacy and safety of dexlansoprazole in long-term therapy (12 months). In addition to gastrin levels, the assessment also included the morphological features of mucosal biopsy specimens collected during follow-up gastroscopies, focusing on the hyperplasia of enterochromaffin cells, signs of epithelial dysplasia or intestinal metaplasia. No significant deviations were found for the study parameters during a treatment spanning 1 year. As in other PPIs, the level of gastrin increases more than twofold during the first 3 months of treatment, and then stabilizes without any clinical and morphological consequences. The efficacy of long-term therapy in terms of controlling reflux symptoms and improving patients' quality of life were retained over the course of maintenance treatment during a follow-up period of 1 year $[35,38]$.

\section{Summary}

Dexlansoprazole, a new-generation proton pump inhibitor, marks a significant progress in the treatment of diseases related to hydrochloric acid, primarily gas- troesophageal reflux disease in all its forms. A group that may particularly benefit from dexlansoprazole treatment comprises patients with symptoms of nocturnal reflux and sleep disorders secondary to GERD [39]. Moreover, dexlansoprazole is very effective in the healing and maintenance of healing of lesions caused by reflux erosive oesophagitis. Dexlansoprazole is a right-handed enantiomer of lansoprazole exhibiting greater efficacy in the inhibition of gastric acid production. Compared to other PPIs, it has a unique mechanism of releasing the active ingredient. Consequently, the drug concentration in the blood and the proton pump inhibition effect are maintained for much longer. Dexlansoprazole efficacy is not dependent on meal, which guarantees better compliance and cooperation with the patient and high efficiency in everyday clinical practice. Crucial advantages of the drug include its optimum safety profile and low risk of adverse interactions with concurrently taken medications. Dexlansoprazole addresses an important part of previously unmet needs in the treatment of gastroesophageal reflux disease.

\section{References}

1. Robinson M. Clinical pharmacology of proton pump inhibitors. Drugs 2003; 63: 2739-54.

2. Blume H. Pharmacokinetic drug interactions profiles of proton pump inhibitors. Drug Safety 2006; 29: 769-84.

3. Andersson T, Rohss K, Bredberg E, Hassan Alin M. Pharmacokinetics and pharmacodynamics of esomeprazole, the S-isomer of omeprazole. Aliment Pharmacol Ther 2001; 15: 1563-9.

4. Banyś AS. Kryteria optymalnego wyboru inhibitora pompy protonowej (IPP) dla chorych leczonych w oddziale intensywnej terapii. Farm Współ 2009; 2: 231-5.

5. Brett $\mathrm{S}$. The use of proton pump inhibitors for gastric acid supression in critical illness. Crit Care 2005; 9: 45-50.

6. Hirota K, Kudo M, Hashimoto H, et al. The efficacy of preanesthetic proton pump inhibitor treatment for patients on longterm H2 antagonist therapy. Anesth Analg 2005; 101: 1038-41.

7. Katsuki H, Yagi $H$, Arimori K, et al. Determination of R- and S-lansoprazole using chiral stationary-phase liquid chromatography and their enantioselective pharmacokinetics in humans. Pharm Res 1996; 13: 611-5.

8. Hershcovici T, Jha LK, Fass R. Dexlansoprazole MR - A review. Ann Med 2011; 43: 366-74.

9. Behm BW, Peura DA. Dexlansoprazole MR for the management of gastroesophageal reflux disease. Expert Rev Gastroenterol Hepatol 2011; 5: 439-45.

10. Woroń J. Dekslansoprazol - postęp w leczeniu chorób górnego odcinka przewodu pokarmowego zależnych od kwasu solnego. Terapia 2015; 6: 106.

11. Abel C, Desilets AR, Willett K. Dexlansoprazole in the treatment of esophagitis and gastroesophageal reflux disease. Ann Pharmacother 2010; 44: 871-6.

12. Boparai V, Rajagopalan J, Triadafilopoulos G. Guide to the use of proton pump inhibitors in adult patients. Drugs 2008; 68: 925-47. 
13. Lee RD, Vakily M, Mulford D, et al. Clinical trial: the effect and timing of food on the pharmacokinetics and pharmacodynamics of dexlansoprazole MR, a novel dual delayed release formulation of a proton pump inhibitor - evidence for dosing flexibility. Aliment Pharmacol Ther 2009; 29: 824-33.

14. Lee RD, Mulford D, Wu J, Atkinson SN. The effect of time-of-day dosing on the pharmacokinetics and pharmacodynamics of dexlansoprazole MR: evidence for dosing flexibility with a dual delayed release proton pump inhibitor. Aliment Pharmacol Ther 2010; 31: 1001-11.

15. Gunaratnam NT, Jessup TP, Inadomi J, Lascewski DP. Sub-optimal proton pump inhibitor dosing is prevalent in patients with poorly controlled gastroesophageal reflux disease. Aliment Pharmacol Ther 2006; 23: 1473-7.

16. Kahrilas PJ, Shaheen NS, Vaezi MF. American Gastroenterological Association Institute technical review on the management of gastroesophageal reflux disease. Gastroenterology 2008; 135: 1392-413.

17. Coelho MA, Henry A. Diagnosis and management of gastroesophageal reflux disease. ABCD Arq Bras Cir Dig 2014; 27: 210-5.

18. Moraes-Filho JPP. Doenca do refluxo gastroesofagico de dificil tratamento. RBM Rev Bras Med 2012; 69: 41-6.

19. Savarino V, Savarino E, Parodi A, et al. Functional heartbun and non-erosive reflux disease. Dig Dis 2007; 25: 172-4.

20. Ruigomez A, Johansson S, Wernersson B, et al. Gastroesophageal reflux disease in primary care using changes in proton pump inhibitor therapy as an indicator of partial response. Scand J Gastroenterol 2012; 47: 751-61.

21. Chey WD, Mody RR, Izat E. Patient and physician satisfaction with proton pump inhibitors (PPIs): are there opportunities for improvement? Dig Dis Sci 2010; 55: 3415-22.

22. Hsu PI, Lu CL, Wu DC, et al. Eight weeks of esomeprazole therapy reduces symptom relapse, compared with 4 weeks, in patients with Los Angeles Grade A or B erosive esophagitis. Clin Gastroenterol Hepatol 2015; 13: 859-66.

23. Rubenstein JH, Nojkov B, Korsnes S, et al. Oesophageal hypersensitivity is associated with features of psychiatric disorders and the irritable bowel syndrome. Aliment Pharmacol Ther 2007; 26: 443-53.

24. Dąbrowski A. Farmakoterapia choroby refluksowej. Gastroenterol Prakt 2012; 4: 22-8.

25. Kukulka M, Eisenberg C, Nudurupati S. Comparator pH study to evaluate the single-dose pharmacodynamics of dual delayed-release dexlansoprazole $60 \mathrm{mg}$ and delayed-release esomeprazole 40 mg. Clin Exp Gastroenterol 2011; 4: 213-20.

26. Wu MS, Tan SC, Xiong T. Indirect comparison of randomised controlled trials: comparative efficacy of dexlansoprazole vs. esomeprasole in the treatment of gastro-esophageal reflux disease. Aliment Pharmacol Ther 2013; 38: 190-201.

27. Fass R, Chey WD, Zakko SF, et al. Clinical trial: the effect of the proton pump inhibitor dexlansoprazole MR on daytime and nightime heartburn in patients with non-erosive reflux disease. Aliment Pharmacol Ther 2009; 29: 1261-72.

28. Fass R, Chey WD, Zakko SF, et al. The effect of the proton pump inhibitor dexlansoprazole MR on nighttime heartburn and sleep disturbances in patients with gastroesophageal reflux disease. Am J Gastroenterol 2011; 106: 421-31.
29. Sharma P, Shaheen NJ, Perez MC, et al. Clinical trials: healing of erosive oesophagitis with dexlansoprazole MR, a proton pump inhibitor with a novel delayed-release formulation - results from two randomized controlled studies. Aliment Pharmacol Ther 2009; 29: 731-41.

30. Kahrilas PJ, Shaheen NS, Vaezi MF. American Gastroenterological Association Institute technical review on the management of gastroesophageal reflux disease. Gastroenterology 2008; 135: 1392-413.

31. Metz DC, Howden CW, Perez MC, et al. Clinical trials: dexlansoprazole MR a proton pump inhibitor with dual delayed-release technology effectively controls symptoms and prevents relapse in patients with healed erosive eophagitis. Aliment Pharmacol Ther 2009; 29: 742-54.

32. Fass R, Inadomi J, Han G, et al. Maintenance of heartburn relief after step-down from twice-daily proton pump inhibitor to once-daily dexlansoprazole modified release. Clin Gastroenterol Hepatol 2012; 10: 247-63.

33. Hansten PD, Horna JR. Top 100 drug interactions 2015. Freeland, H\&H Publications 2014

34. Bazire S. Psychotropic drug directory 2014. Dorsington, Lloyd-Reinhold Communications 2014.

35. Peura DA, Metz DC, Dabholkar AH, et al. Safety profile of dexlansoprazole MR, a proton pump inhibitor with a novel dual delayed release formulation: global clinical trial experience. Aliment Pharmacol Ther 2009; 30: 1010-21.

36. Kukulka M, Wu J, Perez MC. Pharmacokinetics and safety of dexlansoprazole MR in adolescents with symptomatic GERD. JPGN 2012; 1: 41-7.

37. Kukulka M, Nudurupati S, Perez MC. Pharmacokinetics and safety of dexlansoprazole MR in pediatric patients with symptomatic gastroesophageal reflux disease. Clin Exp Gastroenterol 2014; 7: 461-71.

38. Dabholkar AH, Han C, Paris M, et al. The 12 month safety profile of dexlansoprazole a proton pump inhibitor with a dual delayed release formulation in patients with gastroesophageal reflux disease. Aliment Pharmacol Ther 2011; 33: 366-77.

39. Dąbrowski A. Dekslanzoprazol o zmodyfikowanym uwalnianiu - inhibitor pompy protonowej nowej generacji. Gastroenterol Prakt 2015; 3: 55-8.

Received: 23.11 .2015

Accepted: 4.12 .2015 